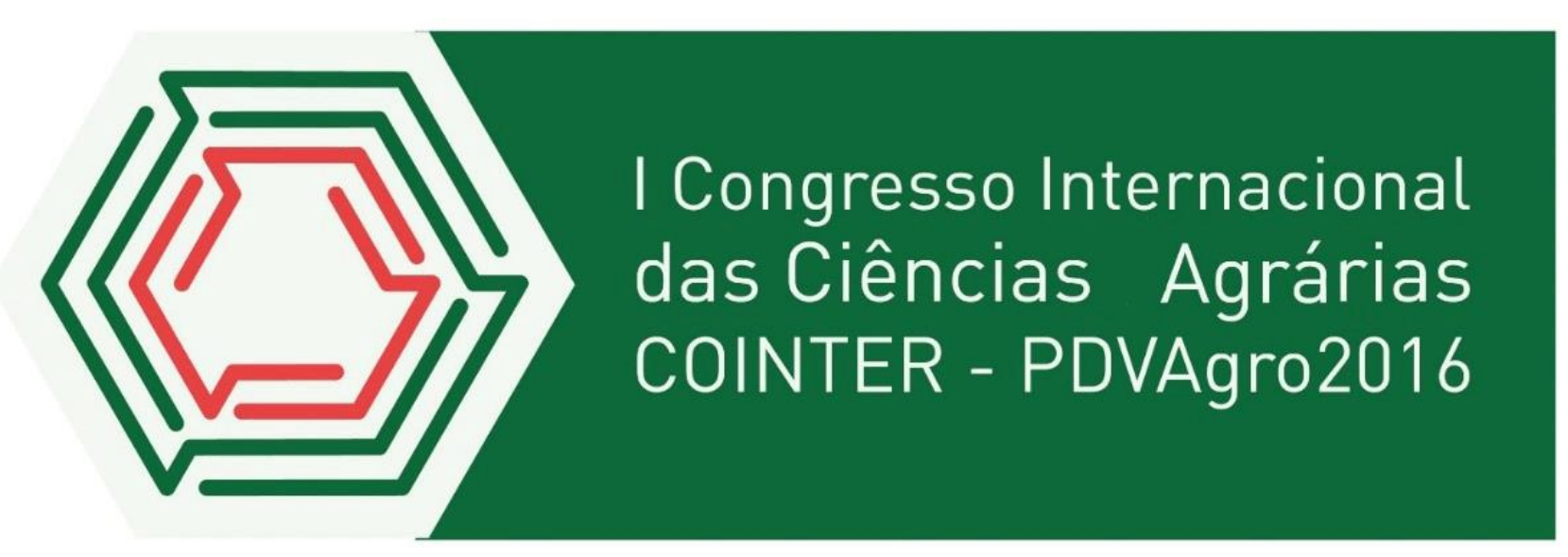

\title{
OS IMPACTOS DA INTERNACIONALIZAÇÃO NA ÁREA DE PESQUISA NO CAMPUS DE VOCAÇÃO AGRÍCOLA.
}

\author{
Apresentação: Comunicação Oral
}

\begin{abstract}
Kaline Soares da Silva ${ }^{1}$; Elielma Josefa de Moura ${ }^{2}$; Kilma Lima da Silva Viana ${ }^{3}$; Edisio Raimundo
\end{abstract} da Silva ${ }^{4 ;}$ Erick Viana da Silva ${ }^{5}$

\section{Resumo}

Este artigo tem como objetivo analisar os impactos da internacionalização na área de pesquisa num campus de vocação agrícola, no estado de Pernambuco-PE, durante o período de transição de Escola Agrotécnica Federal -EAF para Instituto Federal de Pernambuco- IFPE. No IFPE temos o escopo de ensino, pesquisa e extensão, nesse trabalho focamos na área de pesquisa, para saber como funciona o trabalho de internacionalização nesse escopo. O campo de Pesquisa foi constituído pelo campus Vitória de Santo Antão que se encontrava na condição de Escola Agrotécnica Federal quando da criação dos Institutos Federais no ano de 2008. O objeto de pesquisa foi o IFPE, a gestora de pesquisa do campus e análise de documentos disponíveis que relatem sobre essa política de internacionalização. Usamos a fundamentação teórica da gestão do conhecimento, que os seus precursores observaram que o processo de construção do conhecimento diz respeito á crenças e compromissos, quando uma organização sofre mudanças, as crenças de cada indivíduo que compõem a organização pode tornar-se uma barreira difícil de romper assim tendo dificuldade para se acostumar com o novo modelo que a organização está tomando. Evidenciamos como principais resultados a sistematização de um arcabouço de dados e informações disponíveis na instituição e que podem ser utilizados, posteriormente, como um instrumento de gestão do conhecimento institucional. Por fim, a internacionalização dentro do IFPE ainda está longe do que está posto em documentos norteadores, mas com o trabalho dos gestores e setores envolvidos é possível que ela seja mais trabalhada e assim funcione da forma que foi planejada quando se criou os documentos oficiais sobre.

Palavras-Chave: Gestão do conhecimento, Institutos Federais, Internacionalização.

\footnotetext{
${ }^{1}$ Bacharelado em agronomia, Instituto Federal de Pernambuco, kalis.soares8@gmail.com

2 Bacharelado em agronomia, Instituto Federal de Pernambuco, elielmamoura@outlook.com

${ }^{3}$ Professora de pedagogia, Instituto Federal de Pernambuco, kilma.viana@vitoria.ifpe.edu.br

${ }^{4}$ Professor de produção animal e vegetal, Instituto Federal de Pernambuco, edisio.silva@vitoria.ifpe.edu.br

${ }^{5}$ Professor de administração, Instituto Federal de Pernambuco, Erick.viana@vitoria.ifpe.edu.br
} 


\section{Introdução}

Em 02 de junho de 1954 ocorreu a criação da Escola de Magistério de economia rural doméstica em Vitória de Santo Antão. Em 1954 com a introdução do curso técnico em agropecuária ocorreu à nomeação da Escola agrotécnica Federal de Vitória de Santo Antão.

O INSTITUTO FEDERAL DE EDUCAÇÃO, CIÊNCIA E TECNOLOGIA de PERNAMBUCO (IFPE), instituição criada nos termos da Lei $n^{\circ}$. 11.892, de 29 de dezembro de 2008, vinculada ao Ministério da Educação, possui natureza jurídica de autarquia, sendo detentora de autonomia administrativa, patrimonial, financeira, didático-pedagógica e disciplinar. (BRASIL, 2009).

O IFPE desde sua implantação tem como função contribuir com o desenvolvimento educacional e socioeconômico das regiões que estão localizadas em território brasileiro e nesse consolidado de institutos federais sempre preservarem a relação de ensino, pesquisa e extensão.

A proposta de constituição de uma política organizacional e gestão do conhecimento para Instituto Federal de Educação Ciência e Tecnologia de Pernambuco coincidem com as mudanças que estão acontecendo em ambiente interno e externo à organização como também, a instalação de novas políticas públicas.

Coube ao governo à missão de trabalhar com a nova marca, respeitando a história centenária das novas instituições, assim revelando uma nova institucionalidade aliada às políticas públicas, articular políticas públicas que facilitem o acesso à educação profissional estabelecendo mecanismos de inclusão e também a permanência em êxito.

Nesse quadro contínuo de mudanças organizacionais, é quase impossível que os participantes destas aceitem sem alguma resistência. Logo é de função da gestão, observando estes elementos, estabelecer estratégias para colaborar com a condução do processo.

É com base em organizações internacionais tais como, Banco Interamericano de Desenvolvimento (BDI), por exemplo, que o Brasil teve que priorizar os investimentos na educação assim tornando-a mais profissional e com base técnica, tendo em vista um baixo custo, logo acessível para a maioria da sociedade e também em um curto período de tempo.

Diante a criação dos IF's existe a preocupação de uma organização multicampi, para que sejam atendidos os termos da lei.

Trata-se de um projeto progressista que entende a educação como compromisso de transformação e de enriquecimento de conhecimentos objetivos capazes de modificar a vida social e de atribuir-lhe maior sentido e alcance no conjunto da experiência humana, proposta incompatível com uma visão conservadora de sociedade. Trata-se, portanto, de uma estratégia de ação política e de transformação social (BRASIL, 2008). 
Concomitantemente aos movimentos políticos e de reestruturação e implementação do modelo de educação pública de formação profissional e tecnológica no formato dos Institutos Federais (IF's) outras ações aconteciam patrocinadas pelo governo federal no sentido de provocar avanços em setores estratégicos tais quais a formação de profissionais qualificados para novas exigências tecnológicas e geração de processos de inovação tecnológica. Nesse sentido, podemos citar o Programa Ciências sem Fronteiras que enviou mais de 100.000 estudantes à universidades estrangeiras para cursarem graduação e pós-graduações em áreas previamente definidas como estratégicas para o desenvolvimento do país, segundo o governo. Esse movimento, por si só, provocou de forma impositiva mudanças necessárias à implementação de estruturas nos IF's que fossem responsáveis pelo tratamento e assessoramento das questões ligadas às relações internacionais. Nesse trabalho buscaremos analisar sob o enfoque da Gestão do Conhecimento esse momento de transição de Escolas Agrotécnicas para Institutos Federais com foco em uma dimensão específica, a internacionalização dentro da área de pesquisa.

\section{Fundamentação Teórica}

De acordo com Nonaka e Takeuchi (1997), os precursores do estudo da Gestão do conhecimento, criam uma "Teoria da Criação do Conhecimento Organizacional", eles observam que o processo de construção do conhecimento diz respeito á crenças e compromissos. É um processo humano dinâmico de justificar a crença pessoal com relação a verdade. (NONAKA E TAKEUCHI, 1997, pag.63).

Segundo os autores é um processo de duas dimensões: uma ontológica e outra epistemológica. A dimensão ontológica diz que o conhecimento só é criado por indivíduos, que justifica que um conhecimento organizacional seja entendido como um processo que amplia o conhecimento criado pelos indivíduos. Com relação á dimensão epistemológica, está baseada no conhecimento tácito e explícito, nessa dimensão o homem faz uma reflexão sobre o conhecimento produzido por ele próprio. Os autores diferenciam o conhecimento tácito do conhecimento explícito: "O conhecimento tácito é pessoal, específico ao contexto e, assim, difícil de ser formulado e comunicado. Já o conhecimento explícito refere-se ao conhecimento transmissível em linguagem formal e sistemática." (NONAKA E TAKEUCHI, 1997, pág. 65.).

Mas existem modos de conversão deste conhecimento, para os autores existem pelo menos quatro: socialização, externalização, combinação e internalização. Socialização é a conversão tácitotácito, onde ocorre o compartilhamento de conhecimento, é o "fazer junto" e compartilhar as vivências cotidianas. A externalização é a conversão tácito-explicito, é aquela que promove a reflexão de interação entre os indivíduos. É um processo que se expressa basicamente através da linguagem 
escrita e é a chave para a criação do conhecimento, pois cria conceitos novos. A combinação é a conversão explícito-explícito é aquela que os indivíduos trocam e combinam o conhecimento através de reuniões, conversas telefônicas ou redes de internet. A internalização é "o processo de incorporação do conhecimento explícito no conhecimento tácito" (NONAKA e TAKEUCHI, 1997, p.77), provocando mudança e enriquecimento das práticas individuais, grupais e coletivas.

Para Nonaka e Takeuchi, as condições capacitadoras da criação do conhecimento são: a intenção estratégica da empresa em atingir suas metas mediante o desenvolvimento da capacidade organizacional de adquirir, criar, acumular e explorar o conhecimento; a autonomia de ação de todos os membros da organização a partir de uma base compartilhada de informações; a flutuação e caos criativo estimuladores da interação da empresa com o ambiente externo para captação dos sinais ambientais que possam possibilitar a exploração da ambiguidade para aprimoramento pela organização do seu próprio sistema de conhecimento; a redundância, considerando que a superposição intencional de informações sobre as atividades da empresa, responsabilidade da gerência e sobre a empresa como um todo promove o compartilhamento do conhecimento tácito, pois os indivíduos conseguem sentir o que os outros estão tentando expressar; e promoção de variedade de requisitos informacionais que permitam a empresa lidar com a complexidade da realidade. (NONAKA e TAKEUCHI, 1997, p.94).

Quando o conhecimento tácito e o conhecimento explícito interagem, pode ser que haja uma inovação, um novo tipo de pensamento, forma de agir e trabalhar.

A criação do conhecimento organizacional é uma interação contínua e dinâmica entre o conhecimento tácito e explícito.

No cenário organizacional esse tipo de processo dá-se através da interação entre pessoas $\mathrm{x}$ pessoas e pessoas x ambiente. Para Nonaka e Takeuchi(1997) "O verdadeiro contexto no qual ocorre grande parte da conversão do conhecimento é o nível de equipe".

A mudança, no entanto, é marcada por um processo formal e burocrático. Porém O aprendizado cria flexibilidade e agilidade para que a organização possa lidar com a incerteza e faz com que as pessoas possam ser capazes de gerar continuamente novas formas de criar os resultados desejados pela organização. Por isso, as mudanças que caminham lado a lado com o aprendizado criam raízes, em vez de ser transitórias. (NONAKA e TAKEUCHI, 1997).

Contudo, com o poder do conhecimento os participantes da organização traduz o mesmo em imagem, produto e serviço internamente e externamente, é necessário que o conhecimento produzido seja mantido dentro da organização independente de quem o produziu. 


\section{Metodologia}

O campo de Pesquisa foi constituído pelo campus do Instituto Federal de Pernambuco que se encontrava na condição de Escola Agrotécnica quando a criação dos Institutos Federais. O objeto de pesquisa foi o IFPE e o sujeito à antiga gestora de pesquisa do campus Vitória de Santo Antão. Usamos como instrumentos análise de documentos norteadores e entrevista semiestruturada. A pesquisa teve dois momentos. O primeiro realizado através da análise de documentos, que, no caso, aqueles pospostos pelo Governo Federal que trata sobre a política de internacionalização e outros derivados da necessidade de normatizações internas. Com base nessas análises, o segundo momento consistiu na realização de entrevista semiestruturada com o gestor, sujeito da pesquisa.

A entrevista foi realizada com a antiga gestora de pesquisa, a qual a partir de então será chamada de Gestor P, com tempo na função de um ano e três meses. A entrevista com a gestora foi presencial.

As respostas estiveram em algumas situações relacionadas com atividades realizadas em exercícios de gestores que os antecederam.

O instrumento de coleta de dados foi composto por um questionário construído com 11 perguntas com o objetivo de perceber através do depoimento do sujeito de que forma o processo de internacionalização ocorreu no campus e na área em questão.

\section{Resultados e Discussão}

No primeiro momento, o objetivo foi fazer a avaliação documental, a partir deste documento pudemos verificar que, de acordo com o Fórum de Relações Internacionais dos Institutos Federais (FORINTER), desde a sua criação possui o papel de criar redes de cooperação para, assim, poder fazer a troca de experiências com todo o mundo. É de extrema importância que dentro do Instituto exista uma política de internacionalização e para que haja bom funcionamento é de extrema importância o papel de apoio da instituição à implementação dessa política. Continuando a análise do documento pode-se também afirmar que as assessorias internacionais dos IF's vêm fazendo um trabalho de desenvolvimento em escala vertical, esses organismos institucionais buscam apoiar atividades relacionadas com cooperação internacional por sua natureza.

Dentro desse fórum em interação com a Secretaria de Educação Profissional e Tecnológica do Ministério da Educação (SETEC/MEC), houve a criação do documento de Política de Relações Internacionais dos Institutos Federais de Educação, Ciência e Tecnologia, por meio de discussões entre os participantes do fórum, inicialmente neste documento eles alegam que é documento não 
definitivo e também depende da realidade de todos os campi para fazer com que as medidas ditas no mesmo sejam cumpridas. As relações internacionais representam condições fundamentais para um bom desenvolvimento institucional, tornando-se extremamente importante para que os alunos dos campi tenham o conhecimento de outras culturas e desenvolvendo um diálogo amplo para a troca de experiências existentes em seu país de origem, para isso, é fundamental que haja a criação de laços fronteiriços com os diversos países da região.

Essa política de relações internacionais serve como base para que este fórum cumpra com uma lista de objetivos, desposto neste documento, como por exemplo, Desenvolver gestões articuladas entre os Institutos Federais e a SETEC/MEC, por meio da Assessoria Internacional desta Secretaria de Governo; Proporcionar visibilidade às ações dos Institutos Federais, em âmbito nacional e internacional. A importância dessa política dentro dos IF's é a internacionalização como intercâmbio de conhecimentos e aprimoramento de estudantes, professores e técnicos administrativos, Internacionalização como estratégia de desenvolvimento, repercutirá no desenvolvimento econômico, político e social dos países participantes, como promoção da solidariedade entre os países à cooperação internacional necessita estar baseada em solidariedade e respeito mútuo, e na promoção de valores humanísticos e diálogos interculturais, sendo constantemente encorajada, estão ligados a uma determinada área geográfica, mas também estão comprometidos com projetos e programas mais amplos.

Para ocorrer a implementação dessa política no IFPE foram despostas estratégias criação e Estruturação das Assessorias Internacionais dos Institutos Federais, Capacitação dos Assessores Internacionais e Equipe Técnica, criação de Projetos de Cooperação Técnica entre os IF's e instituições de países em desenvolvimento, sobretudo da América Latina e da África, são fundamentais para o intercâmbio de experiências e a interação com agências e organismos de cooperação nacionais e internacionais, a articulação das Assessorias de Relações Internacionais dos IF's com o Ministério das Relações Exteriores.

O Fórum de Relações Internacionais dos Institutos Federais de Educação, Ciência e Tecnologia pretende ser o interlocutor legítimo para dialogar com as diversas instituições nacionais e internacionais e propor políticas de apoio às atividades de cooperação e intercâmbio internacionais de todos os seus integrantes. Dessa forma, as estratégias de Relações Internacionais, adotadas em conjunto pelos Institutos, possibilitarão que essas instituições ocupem um papel de destaque na construção de um Brasil solidário e desenvolvido, contribuindo para um mundo mais justo. (BRASIL, 2009)

Outro documento institucional analisado foram os relatórios da Assessoria de Relações Internacionais cujos relatos apontavam que em meados do ano de 2013, houve algumas missões 
internacionais, como por exemplo, a ida de 16 docentes de todos os campi, de diversas áreas, realizando a prospecção de cooperação internacional, nos países vizinhos, Argentina, Chile e Portugal. A escolha desses países se deu com base na recomendação da, então, política de governo em estimular a cooperação Sul-Sul. Além disso, havia o desafio de estabelecer cooperação com países de língua inglesa pelo fato de que não havia na comunidade acadêmica público com proficiência neste idioma, nem estrutura formativa institucional que tivesse como objetivo inglês com objetivo Neste mesmo ano, 2013, houve também a implementação do Centro de Língua Estrangeira (CELE), que teve em média 200 estudantes beneficiados no ano de 2013. Sobre o programa Ciências sem Fronteiras (CsF) e Inglês sem fronteiras, o IFPE, em parceria com MEC-SESU, foi realizada a aplicação do TOEFL-ITP e outras ações, como a assinatura de protocolos e acordos com parceiros internacionais dispostos a receber estudantes do IFPE, sem pagamento de taxas; Convênio com o Centro de Estudos Martianos (CEM), criação da Cátedra Martí-Julião no Campus Vitória IFPE, Recebimento de 06 estudantes internacionais provenientes da Universidad de La Plata na área de línguas estrangeiras que estagiaram nos campi Barreiros, Pesqueira, Vitória, Reitoria, Belo Jardim e Garanhuns através de um Programa de Acolhimento a Visitantes Internacionais regulamentado pela Resolução CONSUP IFPE N 05/2013. Nesta ocasião os estudantes foram matriculados no campus Vitória e participavam de aulas à sextas-feiras quando retornavam de seus locus de estágios.

Ao investigar os resultados dos Editais de Programas e Projetos de Extensão no IFPE verificouse a presença de apenas 02 Programas Internacionais institucionalizados por iniciativa autônoma de servidores. Programas cadastrados no IFPE Campus Vitória. Programa Internacional Despertando Vocações Para Licenciaturas (PDVL) e Para Ciências Agrárias (PDVAGRO).

Ao verificar os relatórios finais dos Programas Internacionais citados, pode-se encontrar na consecução das ações a indissociabilidade de atividades locais pesquisa ocorrendo com ampliação dos espaços de ações nacionais e internacionais. Neste aspecto merece menção atividades promotoras de internacionalização institucional com a mobilidade acadêmica internacional acontecida no ano de 2016, de três estudantes de cursos da área das ciências agrárias, os discentes foram estudar por um tempo de 5 meses na Universidad de Chile- INACAP com planos de trabalho na área de pesquisa e realizar os objetivos propostos no plano de atividades.

Em análise de mais um documento, o de POLÍTICA DE PESQUISA, PÓS-GRADUAÇÃO E INOVAÇÃO DO INSTITUTO FEDERAL DE EDUCAÇÃO, CIÊNCIA E TECNOLOGIA DE PERNAMBUCO, sob enfoque da área de pesquisa, uma das funções do documento é estabelecer as políticas orientadoras relacionadas á pesquisa. $\mathrm{O}$ documento orienta na tomada de decisão que se vinculam ás finalidades e aos desafios do IFPE no que concerne ao campo de pesquisa. Sobre a pesquisa procura-se, sempre que possível, o alinhamento com os arranjos produtivos, sociais e 
culturais da região, com vistas às diversas formas de acesso ao conhecimento. Nesse sentido a criação, fortalecimento ou ampliação de algum marcos e programas como fomento, regulamentação, parcerias, socialização, ferramentas facilitadoras, formação, infraestrutura e visibilidade, a junção desses marcos busca assim fazer com que a pesquisa funcione e consiga atrair os discentes á realizar atividades relacionadas contribuindo assim também para o sucesso profissional do estudante.

Nesse segundo momento, foi realizada entrevista semiestruturada com perguntas sobre "Internacionalização na área de pesquisa." Com a respectiva antiga gestora de pesquisa do Campus (P).

Através do depoimento foi possível perscrutar a forma como, quando e se ações relacionadas à política de internacionalização no IFPE - Campus Vitória foram executadas.

Para fins de exposição neste documento, elencaremos na sequência: pergunta do instrumento de coleta de dados, respostas da gestora P. A gestora possui sua área de formação curso na área de licenciatura.

1. Em sua carreira, a senhora já teve alguma experiência com gestão?

GESTORA P: Muitas, desde que conclui a graduação exerço a função de coordenação. Coordenação de um programa governamental, durante quatro anos, depois coordenação de órgão estadual de educação em Pernambuco e no IFPE em quatro áreas de coordenações: graduação, assistência estudantil, relações internacionais e depois pesquisa. Atualmente coordena grupo de pesquisa e programa de extensão.

2. Houve algum tipo de curso de capacitação para que a senhora pudesse exercer essa função?

GESTORA P: A entrevistada é pedagoga, e na pedagogia, um curso de duração de cinco anos, e possui com essa graduação um certificado de coordenação e supervisão escolar, então conclui ser coordenadora por formação.

3. O que o senhor (a) entende como política de internacionalização?

GESTOR P: A política seriam orientações, normalmente essas orientações são derivadas de estratégias das instituições para o alcance de objetivos. As ações são trazidas por alunos e professores, onde os mesmos podem trazer demandas ou experiências fora dos muros da instituição, é necessário não ficar apenas restrito com as coisas que acontecem dentro do Brasil, mesmo porque atualmente isso não é mais possível com as tecnologias de informação e comunicação. Todas as coisas que se referem a algo que vai além do Brasil e fazem interface com nossa realizade, para o Gestor P, é internacionalização. Então um curso de inglês é internacionalização, conversar no Facebook com pessoas de outros países, é internacionalização, são muitas as possibilidades. Agora, a política de internacionalização é algo fomentado dentro da instituição para atividades de 
internacionalização, que aí podem se apresentar como mobilidade, cursos internacionais, formação na área internacional, realização de eventos internacionais.

4. O senhor (a) tem conhecimento da política de internacionalização no IFPE?

GESTOR P: Tenho conhecimento sobre acordos internacionais no IFPE e que nos últimos anos foi uma política que fazia parte do governo federal, no sentido de estimular ações de prospecção e de missões internacionais nas Instituições Federais de Ensino, inclusive com a participação de comitivas de dirigentes para que se pudesse facilitar o entendimento do processo, mas poucos acordos saíram do papel.

5. Dentro do seu tempo de gestão houve alguma reunião específica para tratar de assuntos ligados á internacionalização?

GESTOR P: Não, nenhuma reunião específica. Comentou-se em outras reuniões sobre esse assunto, mas nunca teve uma reunião específica para tratar desse assunto enquanto estava na coordenação de pesquisa. Houve um evento que a ARINTER solicitou, em tempo muito curto, de um dia para o outro, dizendo que viria para o campus Vitória falar sobre internacionalização, mas não foi ligada à coordenação de pesquisa. Como fazia parte da gestão, foi solicitada a presença do gestor de pesquisa, mas houve um atraso e a dificuldade para encontrar alunos ainda no campus foi difícil, haveria mais alunos do médio no qual não se interessavam muito, pois a reunião era sobre o Programa Ciências sem Fronteiras, programa que só abrange o ensino superior. Havia alunos do superior, dois ou três que estavam presentes.

No escopo das cinco primeiras perguntas pudemos verificar que há um conhecimento por parte da gestora. Pode-se verificar, também que a capacidade de tratar especificamente do tema por parte da gestora se dá ao fato de, especifamente, aquele gestor ter um histórico de experiências relacionadas à coordenação de programas e de assuntos relativos à internacionalização pois dentro do tempo de gestão da mesma, não houve alguma reunião sequer para tratar do assunto separadamente.

6. Dentro do campus existe algum tipo de ação, programa ou projeto de internacionalização?

GESTOR P: Na Pró-reitoria de Extensão e na coordenação do campus o PDVL é cadastrado como programa de extensão, mas existe um programa dentro da pesquisa que se chama Projeto despertando vocações para as licenciaturas, e eles estão investigando sobre esse programa que está cadastrado na extensão, mas que abrange ensino, pesquisa e extensão. Mas fora esse ai, não tem nenhum projeto que tenha o foco na internacionalização. Esse não tem foco na internacionalização, mas ele investiga um programa internacional.

Como verificado na análise de documentos, no IFPE existem apenas dois Programas Internacionais cadastrados por servidores e em execução, ambos do campus Vitória de Santo Antão. A experiência de internacionalização como verificada na análise documental já ocorria no campus Vitória mesmo antes da implentação dos Programas Internacionais.

7. Existe algum recurso disponível apenas para internacionalização?

GESTOR P: Na pesquisa, não. Quando estava na área de relações internacionais houve a solicitação de bolsas mas havia algum programa jurídico que não podia. No ano passado, na época das eleições, falaram que iriam fazer um edital para a mobilidade estudantil mas não era ligado à pesquisa. Era um edital específico ligado a ARINTER, mas não surgiu esse edital ainda. A entrevistada também pontuou que o estudante que estava fazendo o Programa Ciências sem Fronteiras, poderia esta desenvolvendo pesquisa, também, porém não era isso que se observava, o foco era apenas em ensino. Você sai daqui apenas para estudar lá fora, diferente da internacionalização do PDVL e PDVAgro, os alunos que fazem mobilidade não vão apenas para estudar, lá eles fazem ensino, pesquisa e extensão. Mas isso não é uma política do instituto e sim do programa 
8. Como você observa o desempenho da direção geral e professores em articular ações para incentivar mais os alunos para ir à busca do "aluno de excelência" dentro do campus?

GESTOR P: A gente tem alguns problemas, no ensino técnico, médio integrado, por exemplo, nós temos um problema que é o tempo. O aluno ele estuda de manhã e tarde, pesquisa pra eles é quase loucura porque eles estudam manhã e tarde e só tem a noite para estudar e de noite seria o único tempo que eles teriam para fazer pesquisa, mas como o foco de qualquer instituição de educação é o ensino então, lógico que, não iremos prejudicar esse menino, então se faz uma pesquisa muito simples, ou final de semana na correria. Então não existe um incentivo, apesar de existir o PIBIC Téc., não existe uma organização da instituição, de aula vaga, ou dia vago para que esse aluno possa fazer pesquisa de qualidade. Com relação ao ensino superior eles têm tempo suficiente, e o professor ver que o campus é um campus que está crescendo na pesquisa, todo ano tem um acréscimo de bolsa, os professores estão se envolvendo mais com a pesquisa, hoje em dia existem mais de 12, os alunos estão fazendo mais publicações, mas isso não é uma coisa de todos os professores, existem 90 professores. O GESTOR P diz não lembrar muito bem, mas, continua, por exemplo, se na instituição tem 60 bolsas, tem em torno 20 orientadores, devem existir no máximo 30 professores, então a maioria dos professores se envolve com extensão ou só ensino. É mais fácil para o aluno do superior conseguir o mérito de "aluno de excelência" por conta da carga horária, e também porque do ensino superior valoriza mais a pesquisa, porque a orientação de um técnico não entra nem no currículo Lattes.

9. Sobre o processo de internacionalização disposto em documentos pelo governo federal, você o acha burocrático?

GESTOR P: A internacionalização é uma orientação que vem do $M E C$, de cima, do governo. Nesse caso eles orientam, eles dizem assim: "as instituições precisam se internacionalizar" só que é uma orientação que na hora da avaliação do curso, existe um item lá "internacionalização" e que pode computar positivamente na avaliação (burocrática) do curso. No entanto, não considero isso a questão principal. O mais importante em internacionalizar é poder trazer para dentro da instituição e da formação dos estudantes uma visão contemporânea, atualizada de um mundo sem fronteiras. Nesse sentido não considero a internacionalização um processo burocrático. Pelo contrário, a internacionalização de uma Instituição de Ensino não se faz pelas assessorias internacionais, Se realiza na prática dos atores da comunidade acadêmica. A gestão tem a função de ser uma facilitadora, estimuladora e deixar as relações burocráticas mais fluídas para que os professores, estudantes e técnicos possam agir num ambiente internacionalizado institucionalmente.

Por fim, perguntamos se a entrevistada teria mais alguma contribuição para acrescentar a entrevista e ela disse que não.

\section{Conclusões}

Nesse sentindo, é visível que o processo de institucionalização da internacionalização, na área da pesquisa passa por um processo delicado. A discussão sobre a política de internacionalização dentro da área de pesquisa não é um fato isolado de um contexto, mas faz parte de uma construção histórica, desde a criação do primeiro projeto para discussão de tal. É imprescindível a construção de procedimentos difusores de informações que possam desde a estrutura organizacional de gestão da instituição aos atores que atuam na ponta com servidores de ação finalística e estudantes. Percebemos no depoimento que dentro do escopo de pesquisa que a internacionalização ainda é pouco discutida em reuniões e que o conhecimento da gestora sobre o assunto dá-se á sua experiência acadêmica, desde sua graduação e como diretora de Programas Internacionais da área de pesquisa. Portanto, é 
necessário que, para além, de uma reavaliação dos documentos norteadores sobre essa política, façase necessário, também, a democratização das informações institucionais.

É de extrema importância deixar clara essa política de internacionalização, para todos participantes da comunidade acadêmica. Também, é recomendável a inserção de rubrica específica destinada às ações sistêmicas e locais relacionadas à internacionalização. Verifica-se, também, que a área de pesquisa há carência de investimentos, pois as ações de internacionalização já ocorridas foram correlacionadas, via de regra, com exceção do PDVL e PDVAGRO, à área de ensino e, assim, a pesquisa fica afastada da realidade da internacionalização fomentada nos documentos institucionais pela instituição como política da organização e não apenas como ação individual de servidores. É importante que tenha um olhar especial para a área de pesquisa com os estudantes do médio integrado, pois os mesmos tem horário diário cheio, onde não sobra tempo para que o estudante faça pesquisa de forma que tenha um aprendizado e bom aproveitamento do conhecimento dele.

A internacionalização é uma das possibilidades de aumentar as fronteiras físicas e mentais assim concretizando o que antes só era possível encontrar no campo abstrato, ela não é a única possibilidade, mas é a que pode possibilitar ampliar, inovar e ver a vida acadêmica para além da academia.

\section{Referências}

BRASIL, Resolução CONSUP/IFPE n⿳ 32/2015. Aprovado Programa de apoio á pesquisa, inovação e extensão do instituto federal de educação, ciência e tecnologia de Pernambuco (PAPIEX/IFPE).

BRASIL/MEC. Lei $\mathbf{n}^{\circ} 11.892$ de 29 de dezembro de 2008. Institui a Rede Federal de Educação Profissional Científica e Tecnológica, cria os Institutos Federais de Educação, Ciência e Tecnologia, e dá outras providências. Brasília: Presidência da República, 2008.

Os Institutos Federais: uma revolução na educação profissional e tecnológica. Brasília: MEC/SETEC, 2010.

NONAKA, Ikujiro e TAKEUCHI, Hirotaka. Criação do Conhecimento na Empresa: como as empresas geram a dinâmica da inovação. Rio de Janeiro: Campus, 1997.

PEREIRA, Maria Isalma B. Processos de gestão em transformação: Os institutos federais de educação, ciência e tecnologia como "arena política." 2015284 páginas. Dissertação (Doutorado Núcleo de Política Educacional, Planejamento e Gestão da Educação). Universidade Federal de Pernambuco, Pernambuco, 2015. 